\title{
BUILDING DAMAGE IN WESTPORT
}

\author{
*A. L. Andrews
}

The earthquake of 24 May 1968, was the second of damaging intensity to be experienced in Westport recently. The earlier (1962) quake was of smaller magnitude; but centred, as it was, at Westport it was probably felt with comparable intensity there. Restoration of widespread damage it caused undoubtedly reduced the extent of damage from the 1968 earthquake. Nevertheless the survey after the Inangahua earthquake showed clearly that some of the "remedial work" that followed the 1962 earthquake was simply patching up of surfaces, with no structural significance. Not surprisingly. the 1962 wounds so "treated" appeared again in 1968.

There is 1ittle to be learned from the effects of the 1968 earthquake on older buildings, which predominate in the town, that has not already been learned many times after earthquakes have affected similar buildings in New Zealand.

In Westport, as elsewhere, property owners seem to notice the condition of their property only when they have cause to suspect it has been damaged. All defects are then attributed to the most recent obvious cause. Thus common "heat burst" in chimneys, and hoary old fissures, filled with paint and moss, are (quite genuinely) regarded as earthquake damage。

But there was quite extensive and costly damage to Westport from the Inangahua earthquake. Those parts of the town close to the coast are built on dune sand, which shifted and repacked in the familiar manner, disrupting services (drainage and water supply) buried in the ground, distorting buildings, and breaking pavements and street formations. The areas so affected are almost entirely residential, with timber framed and weatherboard clad houses, and fortunately so, for these buildings are almost indestructable by earthquake induced inertia, or by differential movement of the foundations. There has been substantial damage to many of them; but none were at the point of collapse.

Elsewhere in the town, residential and hospital buildings, timber framed with tile roofs and concrete masonry or brick veneer suffered costly and extensive damage to the veneers, though in none was collapse imminent. Many older and some new chimneys were damaged. Damage to new chimneys was generally most apparent at the gathering, where, with construction by current methods, there is a serious weakness.

In the commercial area, old brick bearing wall structures suffered in varying degrees, most usually in the parapets, and there were some cases of collapse of these. I did not have the opportunity to survey the area earlier than a month after the earthquake, by which time the only building to be condemned as a result of the earthquake had already been demolished.

The newer commercial buildings in town suffered, at most, trivial damage, despite some evident disregard of soundly established principles in their design and construction, such as failure to provide adequate seismic gaps between dissimilar parts, and between the buildings. Where new and old abutted, the old suffered in consequence. 
The most interesting damage occurred at a modern plant of steel and reinforced concrete construction, a few miles out of the town. In this structure, bolted connections of a cross braced heavily loaded steel frame failed by shearing the bolts. The high rigidity and unfavourable ductility characteristics of such frames attract to them more damage than would be experienced by an open rigid jointed frame; unless the design compensates by supplying strength to resist larger horizontal loads. In the same complex of buildings, a high level rigid connection between two relatively tall markedly dissimilar structures (rising to about 90' above foundation level), was responsible for spectacular damage at the junction of the connection (a steel stair) to one of them. The concrete of a reinforced concrete landing was pulverised, and fell away from the twisted mats of reinforcing steel. 